\title{
Midterm prognosis and surgical implication for clival chordomas after extended transsphenoidal tumor removal and gamma knife radiosurgery
}

Yoshikazu Ogawa ${ }^{1 *} \mathbb{D}$, Hidefumi Jokura ${ }^{2}$ and Teiji Tominaga ${ }^{3}$

\begin{abstract}
Background: Treating chordoma through surgery alone is often ineffective. Thus, surgery often performed with irradiation, with a reported 5-year survival rate of $60-75 \%$. The clinical course varies, and disease rarity prevents larger number of clinical investigations.

Methods: In total, 19 patients with clival chordomas were retrospectively extracted from our institutional database. They were initially treated with maximal tumor removal using the extended transsphenoidal approach between March 2006 and January 2021. When total tumor removal was achieved, prophylactic irradiation was not performed. If tumor remnants or recurrence were confirmed, Gamma Knife (GK) radiosurgery was performed. The mean followup period was 106.7 months (ranged 27-224 months). The clinical course and prognostic factors were investigated.

Results: Total removal was achieved in 10 patients, whereas 4 patients suffered recurrence and required GK. GK was applied to 11 patients with a 50\% isodose of 13-18 Gy (mean: $15.4 \mathrm{~Gy}$ ), and eight patients remained progression free, whereas three patients suffered repeated local recurrence and died of tumor-related complications. The mean overall progression-free interval was 57.2 months (range: 6-169 months). One male patient died of tumor un-related lung cancer 36 months after the initial treatment, and other patients survived throughout the observational periods. The mean overall survival was 106.7 months (range: 27-224 months). Thus, the 5-year survival rate was $94.7 \%$. Statistical analysis indicated that sex (men), > 15 Gy of 50\% isodose by GK, and screening brain examinations as prophylactic medicine were significant favorable prognostic factors.
\end{abstract}

Conclusions: The favorable outcomes in this investigation suggest the importance of early detection and treatment. Surgery may enable better conditions for sufficient GK doses.

Keywords: Chordoma, Gamma knife radiosurgery, Maximal removal, Prognosis, Transsphenoidal approach

* Correspondence: yogawa@kohnan-sendai.or.jp

'Department of Neurosurgery, Kohnan Hospital, 4-20-1 Nagamachi Minami,

Taihaku-ku, Sendai, Miyagi 982-8523, Japan

Full list of author information is available at the end of the article

(c) The Author(s). 2021 Open Access This article is licensed under a Creative Commons Attribution 4.0 International License, which permits use, sharing, adaptation, distribution and reproduction in any medium or format, as long as you give appropriate credit to the original author(s) and the source, provide a link to the Creative Commons licence, and indicate if changes were made. The images or other third party material in this article are included in the article's Creative Commons licence, unless indicated otherwise in a credit line to the material. If material is not included in the article's Creative Commons licence and your intended use is not permitted by statutory regulation or exceeds the permitted use, you will need to obtain permission directly from the copyright holder. To view a copy of this licence, visit http://creativecommons.org/licenses/by/4.0/ The Creative Commons Public Domain Dedication waiver (http://creativecommons.org/publicdomain/zero/1.0/) applies to the data made available in this article, unless otherwise stated in a credit line to the data. 


\section{Background}

Chordomas arise from the prenatal remnants of the notochord and are frequently located on the midline of the skull base, cervical vertebrae, and sacrum [3]. The incidence rate is only $0.5 \%$ among all intracranial tumors and $1-4 \%$ among skeletal tumors $[1,16,19,22]$. This rarity of the disease has prevented extensive clinical investigations, causing a great discrepancy between the indolent pathological features and the malignant clinical course $[5,7-10$, $12-15]$, with a reported 5-year survival rate of $60-75 \%$. Although the tumor doubling time is rather long for chordomas, repeated local recurrences and dissemination are not unusual because of the invasive growth along the bone marrow $[2,5]$. Tumor control by surgery alone is considered difficult, and thus, most patients are treated using combined therapy with irradiation $[6-9,14,17]$. Because this tumor usually exhibits resistance to conventional radiation therapy and evidence for effective chemotherapy has not yet been established, ion beam therapy including proton or heavy ion beam therapy is expected to provide good tumor control $[6,8,17]$. However once again, the rarity of this disease hinders the accumulation of clinical experiences, and health insurance barely covers treatments with ion beam therapy.

Here, we present a single-center experience of maximal tumor removal of clival chordomas using the extended transsphenoidal approach following Gamma Knife (GK) radiosurgery for visualized remnants or tumor recurrence. The role and the implications of surgery are also discussed.

\section{Methods}

\section{Patients and surgical approach}

This report included 14 men and 5 women aged 41-85 years (mean: 60.4 years) suffering from clival chordomas were included with histological confirmation at the Department of Neurosurgery, Kohnan Hospital between March 2006 and January 2021. The patients were initially treated with maximal tumor removal using the extended transsphenoidal approach with simultaneous removal of the surrounding bone cortex and bone marrow as far as possible within the technical range of skull base repair. Reconstruction of the skull base was performed with autologous fascia tightly sutured to the dural edge of the skull base, fortified with epidural attachment of muscle pieces, and the entire surface of the dural window was wrapped with mucosal flap of the sphenoidal sinus. No type of marsupialization was performed.

\section{Assessment}

All patients underwent axial, coronal and sagittal T1and T2-weighted magnetic resonance (MR) imaging with and without contrast medium (Signa Horizon, General Electric, Milwaukee, WI; 3.0 Tesla system) and bone image computed tomography (CT) (Discovery CT 750 $\mathrm{HD}$, General Electric) preoperatively and just after the operation. Follow-up MR imaging was performed postoperatively for all patients at 6-month intervals after the operation (1.5 Tesla system; Magnetom, Siemens AG, Erlangen, Germany). When gross total removal was achieved, prophylactic irradiation was not performed, and patients were simply observed at 6-month intervals. If tumor remnants were visualized, the GK radiosurgery was applied upon skull base regeneration (usually approximately 3 months after the operation). When tumor recurrence was confirmed, GK radiosurgery was subsequently applied to the visualized tumor bulk; this occurred in all patients except for one female patient (case 16), who was treated with postoperative fractionated irradiation because of her older age ( 85 years). All the patients could be followed up throughout their clinical course with MRI evaluation for 27-224 months (mean: 106.7 months).

Gross total removal was defined as the absence of visible tumor bulk on both during intraoperative findings and postoperative MR imaging.

\section{Radiosurgery planning}

In total, $19 \mathrm{GK}$ treatments were performed for residual or recurrent tumors in 11 patients using four generations of GK (Type B ( $n=1$ treatment), Type C with APS $(\mathrm{n}=1)$, Perfexion $(n=12)$ or Icon $(n=5)$. Except for one hypofractionated treatment (the sixth treatment of case 1), all other treatments were performed in a single fraction. For dose planning, thin-sliced gadolinium-enhanced $\mathrm{T} 1$ and T2 MR images, and heavy T2 images with bone-window CT were used to delineate tumor boarders including the area of bone erosion by the invading tumor (Fig. 1). No margin was added to the tumor margin. The treated tumor volume and prescribed marginal dose were 13-18 Gy using the $50-90 \%$ isodose line (Table 2). We attempted to apply at least $16 \mathrm{~Gy}$ to the margin of the tumor, however, in some cases this dose had to be decreased because of the proximity of the optic apparatus, prior radiation, or large tumor volume.

\section{Pathological examination}

The surgical specimens were immediately fixed for histology and immunohistochemistry with $10 \%$ buffered formalin, then embedded in paraffin, and cut into $3-\mu \mathrm{m}-$ thick serial sections. Hematoxylin and eosin as well as periodic acid-Schiff staining were performed in all cases. The avidin-biotin-peroxidase complex method was applied for immunohistochemical staining, and cell proliferation was assessed with Ki-67 (MIB-1, Dako, 1:100). Immunohistochemically positive cells were counted within at least 1000 background cells in three highpower visual fields including the hot spot and other 


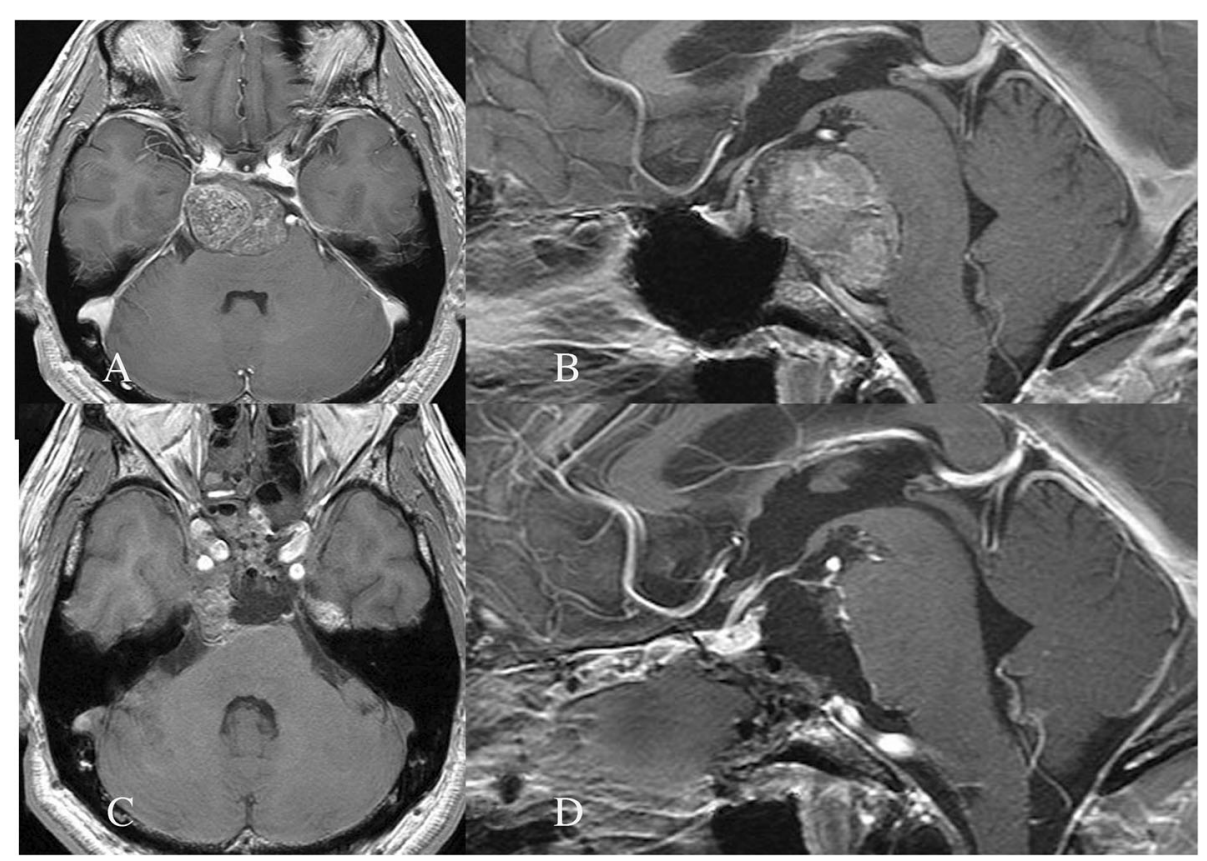

Fig. 1 Head MR imaging with contrast medium showing massive clival tumor compressing the entire pons backward (a: axial image, b: sagittal image); surgery removed $90 \%$ of the tumor was removed except for the right retrocavernous sinus portion (c: axial image $\mathbf{d}$ : sagittal image)

fields, and then indicated as a percentage. Normal lymph nodes were used as positive controls for Ki-67.

\section{Statistical analysis}

Statistical comparisons were made using Statmate 5 software (ATMS Co., Ltd., Tokyo, Japan), and $P$ values of $<$ 0.05 were considered significant. Univariate analysis between groups was performed. Age, sex, preoperative tumor volume, maximum tumor diameter, total removal (yes or no), Ki-67 labeling index (more or less than $10 \%$ ), $50 \%$ isodose of GK (yes or no) and screening brain examination (yes or no) were compared with log-rank analysis. Any variables with a $P$ value of $<0.05$ were considered to be potential independent variables and were entered into the multivariate analysis using the Cox proportional hazard model.

\section{Ethics approval and consent to participate}

The surgical policy was explained preoperatively to the patients and written informed consent was obtained, and the study design was approved by the internal ethics committee of Kohnan Hospital 2021.

\section{Results}

Among the 19 patients enrolled in this study, the most common initial symptom was diplopia due to cranial nerve palsy ( $n=6$ patients), optic nerve dysfunction $(n=2)$, and spontaneous cerebrospinal fluid leakage due to clival erosion with no visible tumor $(n=1)$. Overall, 8 patients were asymptomatic, and the tumors were detected using screening brain examinations as prophylactic medicine. Initial treatments were applied in $17 \mathrm{pa}-$ tients; however, the remaining 2 patients had suffered from re-growth after step-wise tumor removal and radiation therapy (Table 1). All of the tumors extended along the clivus, and eight patients experienced extraarachnoidal localization, whereas the remaining 11 experienced tumor extension into the subarachnoid spaces.

Gross total removal was achieved in 10 patients, and tumor remnants were observed in nine patients, indicating a removal rate of $73-100 \%$ (mean: $92.8 \%$ ). The tumor recurrence developed in four out of 10 patients with gross total removal, which required GK treatment thereafter. The remaining six patients were observed only, and all of them were asymptomatic preoperatively. Postoperative follow-ups continued for 27-224 months (mean: 106.7 months), the overall progression-free intervals were 6-169 months (mean: 57.2 months), and the overall survival was 27-224 months (mean: 106.7 months), except for one male patient, who died of tumor-unrelated lung cancer 36 months after the initial treatment (case 12). Thus, the 5 -year survival rate was 94.7\%.

Preoperative tumor exhibited volumes of $0.17-68.4$ $\mathrm{mL}$ (mean: $16.2 \mathrm{~mL}$ ) and maximum diameters of $8-63$ mm (mean: $32.2 \mathrm{~mm}$ ). Postoperative residual tumors exhibited volumes of $0-6.17 \mathrm{~mL}$ (mean: $1.61 \mathrm{~mL}$ ). GK radiosurgery was performed 19 times for 11 patients with a $50 \%$ isodose of $13-18$ Gy (mean: $15.4 \mathrm{~Gy}$ ). Overall, 8 out of 11 patients remained progression free, whereas 3 
Table 1 Preoperative clinical profile

\begin{tabular}{|c|c|c|c|c|c|}
\hline Case & Age Ranges & Sex & Tumor volume (mL) & Maximum diameter $(\mathrm{mm})$ & Initial symptom \\
\hline 1 & $61-70$ & $\mathrm{~F}$ & 15.1 & 39 & 6 Nerve palsy \\
\hline 2 & $41-50$ & M & 0.73 & 12 & Brain examination \\
\hline 3 & $51-60$ & M & 36 & 50 & $1 \mathrm{TO}, 3 \mathrm{GK}$ \\
\hline 4 & $61-70$ & M & 12.7 & 40 & 6 Nerve palsy \\
\hline 5 & $51-60$ & M & 14.4 & 32 & Incidental \\
\hline 6 & $41-50$ & M & 9.8 & 39 & 1 Removal, 1 FR \\
\hline 7 & $61-70$ & M & 26.4 & 50 & Nasal congestion \\
\hline 8 & $41-50$ & M & 0.98 & 15 & Incidental \\
\hline 9 & $51-60$ & M & Not visible & Not visible & CSF leakage \\
\hline 10 & $41-50$ & M & 11.7 & 30 & Brain examination \\
\hline 11 & $71-80$ & M & 2.52 & 28 & 3,4 Nerve palsy \\
\hline 12 & $71-80$ & M & 5.13 & 27 & 6 Nerve palsy \\
\hline 13 & $61-70$ & M & 3.4 & 20 & Brain examination \\
\hline 14 & $61-70$ & $\mathrm{~F}$ & 12.8 & 41 & 6 Nerve palsy \\
\hline 15 & $51-60$ & $\mathrm{~F}$ & 2.76 & 23 & Brain examination \\
\hline 16 & $81-90$ & $\mathrm{~F}$ & 17.9 & 42 & Unilateral blindness \\
\hline 17 & $51-60$ & M & 68.5 & 52 & Bitemporal hemianopsia \\
\hline 18 & $51-60$ & $\mathrm{~F}$ & 66.5 & 63 & 3,6 Nerve palsy \\
\hline 19 & $51-60$ & M & 0.17 & 8 & Brain examination \\
\hline
\end{tabular}

$F$ female, $M$ male, $T O$ transoral surgery, $G K$ gamma knife, $F R$ fractionated irradiation CSF cerebrospinal fluid

Table 2 Postoperative course

\begin{tabular}{|c|c|c|c|c|c|c|c|}
\hline Case & $\begin{array}{l}\text { Removal } \\
\text { rate (\%) }\end{array}$ & $\begin{array}{l}\text { Tumor volume } \\
\text { at GK }(\mathrm{ml})\end{array}$ & $\begin{array}{l}\text { Marginal } \\
\text { dose (Gy) }\end{array}$ & Isodose (\%) & $\begin{array}{l}\text { PF period } \\
\text { (months) }\end{array}$ & $\begin{array}{l}\text { Overall survival } \\
\text { (months) }\end{array}$ & Treatment and clinical course \\
\hline 1 & 100 & $\begin{array}{l}6.6,3.1,1.0,1.1 \\
7.7,3.2\end{array}$ & $\begin{array}{l}14,14,15,15 \\
14,5 \times 5\end{array}$ & $\begin{array}{l}50,50,50 \\
50,50,50\end{array}$ & 12 & 186 & TS - GK $\times 6-$ \\
\hline 2 & 100 & $\mathrm{~N} / \mathrm{A}$ & $\mathrm{N} / \mathrm{A}$ & $\mathrm{N} / \mathrm{A}$ & 169 & 169 & TS - \\
\hline 3 & 75 & 1.2 & 20 & 90 & 51 & 224 & $\begin{array}{l}\text { TS - GK - GK - GK - TS - GK - TC - CK died from } \\
\text { disease progression to sarcoma }\end{array}$ \\
\hline 4 & 100 & $7.3,17.6,27.8$ & $14,14,15$ & $50,50,50$ & 48 & 62 & TS - GK - GK - TS - TS - GK died from epistaxis \\
\hline 5 & 90 & 2.7 & 16 & 50 & 6 & 165 & TS - TS - GK \\
\hline 6 & 70 & $13.0,3.2$ & 13,12 & 50 & 31 & 100 & $\begin{array}{l}\text { TS - FR(50Gy) - TS - GK - TS - GK died from brain } \\
\text { stem invasion }\end{array}$ \\
\hline 7 & 100 & N/A & N/A & N/A & 69 & 150 & TS - \\
\hline 8 & 100 & $\mathrm{~N} / \mathrm{A}$ & $\mathrm{N} / \mathrm{A}$ & $\mathrm{N} / \mathrm{A}$ & 152 & 152 & TS - \\
\hline 9 & 100 & $\mathrm{~N} / \mathrm{A}$ & $\mathrm{N} / \mathrm{A}$ & $\mathrm{N} / \mathrm{A}$ & 138 & 138 & TS - \\
\hline 10 & 100 & 1.0 & 18 & 52 & 95 & 130 & $\mathrm{TS}-\mathrm{GK}$ \\
\hline 11 & 100 & 2.3 & 16 & 55 & 30 & 127 & $\mathrm{TS}-\mathrm{GK}$ \\
\hline 12 & 95 & 4.5 & 17 & 50 & 38 & 38 & TS - GK died from lung cancer \\
\hline 13 & 100 & $\mathrm{~N} / \mathrm{A}$ & $\mathrm{N} / \mathrm{A}$ & N/A & 115 & 115 & TS - \\
\hline 14 & 80 & 14.5 & 16 & 50 & 21 & 62 & $\mathrm{TS}-\mathrm{GK}$ \\
\hline 15 & 95 & 1.7 & 16 & 50 & 24 & 60 & TS - GK \\
\hline 16 & 73 & $\mathrm{~N} / \mathrm{A}$ & $\mathrm{N} / \mathrm{A}$ & N/A & 15 & 51 & TS - \\
\hline 17 & 91 & 17.6 & 15 & 50 & 19 & 45 & TS - GK \\
\hline 18 & 95 & N/A & $\mathrm{N} / \mathrm{A}$ & N/A & 27 & 27 & TS - \\
\hline 19 & 100 & N/A & $\mathrm{N} / \mathrm{A}$ & N/A & 27 & 27 & TS - \\
\hline
\end{tabular}


Table 3 Prognostic factors of progression free (log-rank analysis)

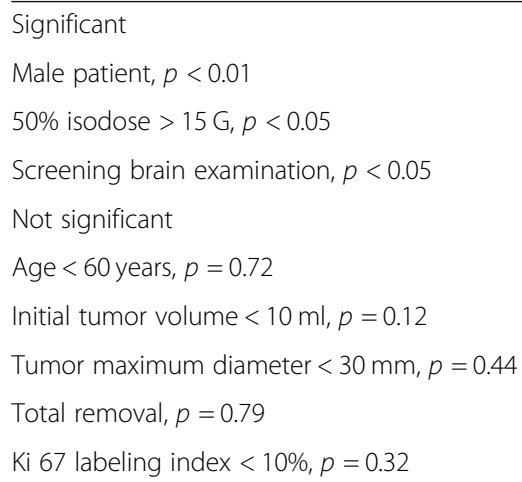

patients suffered repeated local recurrence and died of tumor-related complications. The Ki-67 labeling index ranged from less than 1-25.1\% (mean: 8.91\%). The clinical data are shown in Table 2.

The results show that male patients $(p<0.01)$, who received $>15$ Gy of $50 \%$ isodose at the time of GK radiosurgery $(p<0.05)$, and who received screening brain examination as prophylactic medicine $(p<0.05)$ had a significantly favorable prognosis according to univariate statistical analysis. Gross total removal and a tumor volume of $<1 \mathrm{~mL}$ before GK radiosurgery did not appear to have a significant effect on prognosis. An age of $>60$ years, a tumor volume of $>10 \mathrm{~mL}$, and a maximum tumor diameter of $>30 \mathrm{~mm}$ were not adverse prognostic factors. No statistical significance was observed between patients with Ki-67 labeling indexes of either $>10 \%$ or $<10 \%$ (Table 3). Subsequent multivariate statistical analysis showed significance in male patients $(p<0.02)$, however, the $95 \%$ confidence interval was relatively wide), but not for GK values of $>15$ Gy of $50 \%$ isodose $(P=0.05)$ or screening brain examination $(P=0.08)$. (Table 4$)$.

\section{Illustrative case (case 5)}

A 55-year-old man was admitted to the attendant neurosurgical department with continuous nasal obstructive feeling. Head MR imaging showed a massive clival tumor compressing the entire pons backward, and he was introduced to our institute. Extended transsphenoidal surgery was performed in a step-wise manner, resulting in $90 \%$ of tumor removal without any neurological deficit (Fig. 1). GK radiosurgery was performed 6 months later to the tumor remnants in the right retrocavernous sinus portion with a marginal dose of $16 \mathrm{~Gy}$ (Fig. 2a). He was followed up in 6months intervals, and complete remission was achieved. Since then, 151 months have passed with no evident tumor recurrence (Fig. 2b, c).

\section{Discussion}

According to one meta-analysis for chordomas, the 5-year survival rate of patients is $60-75 \%$, and treatment results have shown little improvement, even with modern surgical procedures [12]. Although the 5-year survival rate in this investigation was $95 \%$ (slightly higher than previously reported) and with no postoperatively acquired neurological deficits, total removal was not a prognostic factor. As such, adjuvant irradiation of this tumor has been confirmed to be essential once again. However, this tumor usually resists conventional radiation therapy with low-dose irradiation to a wide radiation field $[6-9,14,17]$. In contrast, preoperative tumor volume, maximum tumor diameter, however, applying $>15$ Gy of a $50 \%$ isodose had a significant effect, as a previous report has suggested [11]. Although objective surgical goals vary between reports and the ideal relationship between surgery and postoperative GK radiosurgery is unclear $[7,9,13,23]$, the results in this investigation may suggest the importance of reducing maximal tumor volume. This maximal tumor volume reduction provides an adequate condition for sufficient irradiation, including securing a distance from the optic pathway. Accordingly, we attempted to remove the tumor bulk together with the surrounding bone cortex and bone marrow as far as possible within the technical range of skull base repair. Such expansive removal could contribute to dose escalation of irradiation and/or localization of the radiation field.

Screening brain examination was also identified as another prognostic factor, which was applied as prophylactic medicine mainly targeted to un-ruptured cerebral aneurysms or asymptomatic arterial stenosis. Because the efficacy of this approach across a larger population and the costs vary greatly between nations, this system has not become popular in many countries except for Japan. However, the favorable outcomes in this investigation may indicate the importance of early detection and early treatment of this malignant disease. If a tumor is detected, a no wait-and-see approach should be adopted, rather, early surgery should be implemented

Table 4 Multivariate analysis using Cox proportional hazard model

\begin{tabular}{lllllll}
\hline Variables & PE & SE & Wald chi-squared & Precision $\mathbf{p}$ value & Risk ratio & $\mathbf{9 5 \%}$ Cl \\
\hline Sex & 2.260 & 0.925 & 5.968 & 0.014 & 9.591 & $1.563-58.834$ \\
GK $>$ 15 Gy & -0.285 & 0.150 & 3.606 & 0.057 & 0.751 & $0.560-1.009$ \\
Brain examination & 1.212 & 0.705 & 2.955 & 0.085 & 3.361 & $0.843-13.394$ \\
\hline
\end{tabular}

GK gamma knife, $P E$ parameter estimates, $S E$ standard error, $C l$ confidence interval 

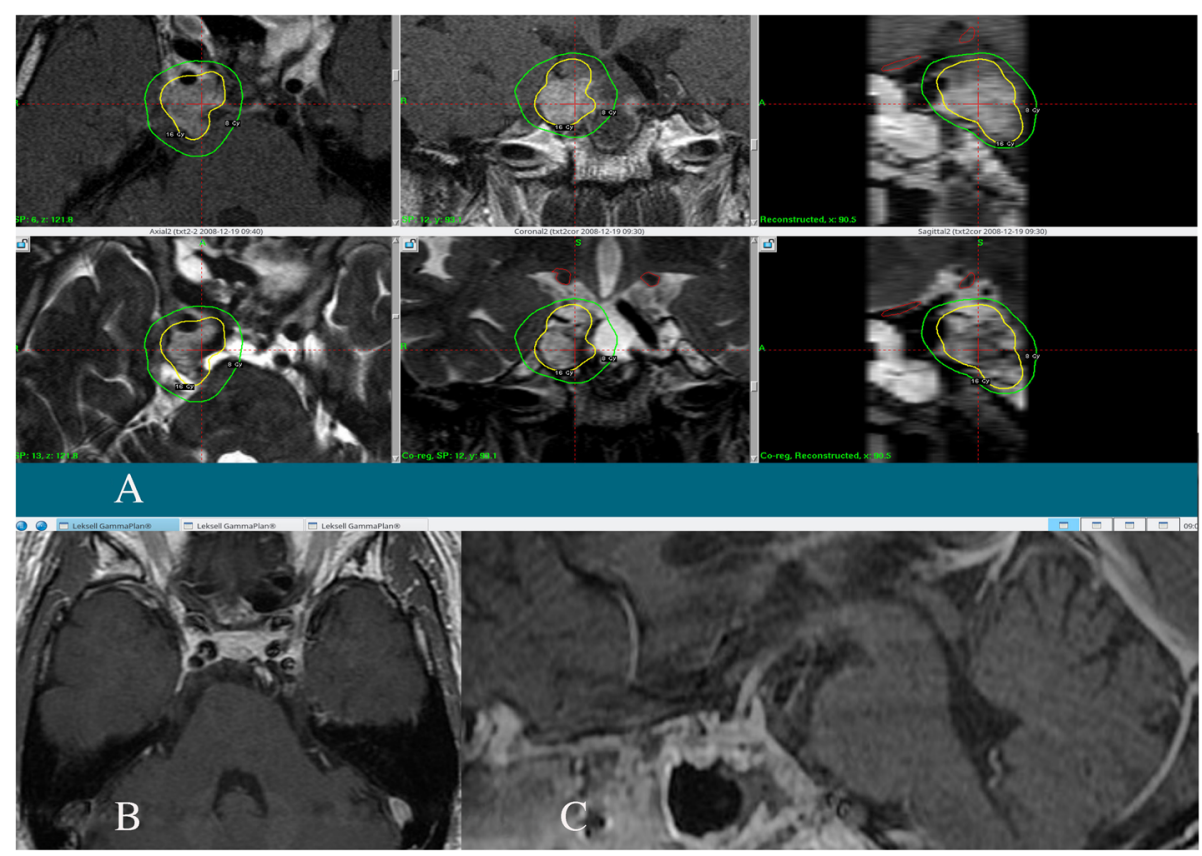

Fig. 2 GK radiosurgery was planned with a marginal dose of $16 \mathrm{~Gy}$. The yellow line indicating $16 \mathrm{~Gy}$, and the green as $8 \mathrm{~Gy}$ a. Follow-up MR imaging revealed complete remission of the tumor (b: axial image, $\mathbf{c}$ : sagittal image)

even for asymptomatic lesions. The extended transsphenoidal approach is considered less invasive and therefore a better approach for treatment.

Pathophysiological investigations revealed the Ki-67 labeling index, p53 overexpression, and receptor tyrosine kinase expression as possible indicators [4, 20, 21]. Another report presumed a prognostic difference between chondroid chordoma and chordoma [18]. No significant differences were found between these parameters in this investigation (data not shown); however, this may be due to the small sample number or differences of treatment protocols.

The limitation of this investigation was the small patient number. Past reports have compared prognosis by conducting meta-analyses of different disease backgrounds and different treatment protocols, including proton beam irradiation. The reported investigation for chordomas and chondrosarcomas using proton and/or carbon beam irradiation showed 2-year progression free survival of $76.8 \%$ and overall survival of $87.2 \%$ [6]. Another proton or carbon beam irradiation showed 5-year progression free survival of $81 \%$ and overall survival of $86 \%$ [17]. To establish standardized treatment guidelines, prospective and larger multi-institutional studies are strongly encouraged.

\section{Conclusions}

The favorable outcomes in this investigation may indicate the importance of early detection and treatment. Surgery may enable favorable conditions for sufficient doses of GK radiosurgery.
Abbreviations

GK: Gamma knife; MR imaging: Magnetic resonance imaging; CT: Computed tomography

\section{Acknowledgements}

None

\section{Authors' contributions}

All authors contributed to the study conception and design. YO was a major contributor in writing the manuscript and performed tumor removal all through the investigated period. $\mathrm{HJ}$ performed all the GK radiosurgery all through the investigated period. And TT gave an essential suggestion and supervised this manuscript. YO wrote the first draft of the manuscript, and all authors commented on previous versions of the manuscript. All authors read and approved the final manuscript.

\section{Funding}

No funding was received for this research.

Availability of data and materials

All the data from in this investigation can be disclosed after the request from the editor-in-chief, and the datasets used and/or analyzed during the current study available from the corresponding author on reasonable request.

\section{Declarations}

Ethics approval and consent to participate

All procedures performed in studies involving human participants were in accordance with the ethical standards of the institutional and/or national research committee and with the 1964 Declaration of Helsinki and its later amendments or comparable ethical standards. The surgical policy was explained preoperatively to the patients and written informed consent was obtained, and the study design was approved by the internal ethics committee of Kohnan Hospital 2021.

Consent for publication

Not applicable 


\section{Competing interests}

The authors declare that they have no conflict of interest.

\section{Author details}

'Department of Neurosurgery, Kohnan Hospital, 4-20-1 Nagamachi Minami, Taihaku-ku, Sendai, Miyagi 982-8523, Japan. Jiro Suzuki Memorial Gamma House, Furukawa Seiryo Hospital, Osaki, Miyagi, Japan. ${ }^{3}$ Department of Neurosurgery, Tohoku University Graduate School of Medicine, Sendai, Miyagi, Japan.

Received: 8 November 2020 Accepted: 11 May 2021

Published online: 22 May 2021

\section{References}

1. Bjornsson J, Wold LE, Ebersold MJ, Laws ER. Chordoma of the mobile spine. A clinicopathologic analysis of 40 patients. Cancer. 1993;71(3):735-40. https://doi.org/10.1002/1097-0142(19930201)71:3<735::AID-CNCR2820710314 $>3.0 . \mathrm{CO} ; 2-8$.

2. Casali PG, Stacchiotti S, Sangalli C, Olmi P, Gronchi A. Chordoma. Curr Opin Oncol. 2007;19(4):367-70. https://doi.org/10.1097/CCO.0b013e3281214448.

3. Chauvel KA, Taillat F, Gille O, Rivel J, Vital JM, Bioulac-Sage P, et al. Giant vertebral notochordal rest: a new entity distinct from chordoma. Histopathology. 2005;47(6):646-6. https://doi.org/10.1111/j.1365-2559.2005. 02168.x.

4. Chen K, Mo J, Zhou M, Wang G, Wu G, Chen H, et al. Expression of PTEN and $\mathrm{mTOR}$ in sacral chordoma and association with poor prognosis. Med Oncol. 2014;31(4):886. https://doi.org/10.1007/s12032-014-0886-7.

5. Ferraresi V, Nuzzo C, Zoccali C, Marandino F, Vidiri A, Salducca N, et al. Chordoma: clinical charateristics, management and prognosis of a case series of 25 patients. BMC Cancer. 2010;10(1):22. https://doi.org/10.1186/14 71-2407-10-22

6. Guan X, Gao J, Hu J, Hu W, Yang J, Qiu X, et al. The preliminary results of proton and carbon ion therapy for chordoma and chondrosarcoma of the skull base and cervical spine. Radiat Oncol. 2019;14(1):206. https://doi.org/1 0.1186/s13014-019-1407-9.

7. Hafez RFA, Fahmy OM, Hassan HT. Gamma knife surgery efficacy in controling postoperative residual chordoma growth. Clin Neurol Neurosurg. 2019;178:51-5. https://doi.org/10.1016/.clineuro.2019.01.017.

8. Hulou MM, Garcia CR, Slone SA, Dugan A, Lei F, Huang B, et al. Comprehensive review of cranial chordomas using national database in the USA. Clin Oncol R Coll Radiol. 2019;31(9):e149-59. https://doi.org/10.1016/j. clon.2019.06.004.

9. Jagerberg M, ElRahal A, Dammann P, Merkler D, Weber DC, Schaller K. Clival chordoma: a single-center outcome analysis. Acta Neurochir. 2017;159(10): 1815-23. https://doi.org/10.1007/s00701-017-3163-7.

10. Jian BJ, Bloch OG, Yang I, Han SJ, Aranda D, Parsa AT. A comprehensive analysis of intracranial chordoma and survival: a systemic review. $\mathrm{Br} J$ Neurosurg. 2011;25(4):446-53. https://doi.org/10.3109/02688697.2010.54 6896.

11. Kim JH, Jung HH, Chang JH, Chang JW, Park YG, Chang WS. Gamma knife surgery for intracranial chordoma and chondrosarcoma: radiosurgical perspectives and treatment outcomes. J Neurosurg. 2014;21:88-97.

12. Leah P, Dower A, Vescovi C, Mulcahy M, Al KD. Clinical experience of intracranial chordoma - a systematic review and meta-analysis of the literature. J Clin Neurosci. 2018;53:6-12. https://doi.org/10.1016/j.jocn.2018. 04.008.

13. Liu AL, Wang ZC, Sun SB, Wang MH, Luo B, Liu P. Gamma knife radiosurgery for residual skull base chordomas. Neurol Res. 2008;30(6):557-61. https://doi. org/10.1179/174313208X297878.

14. Sanusi O, Arnaout O, Rahme RJ, Horbinski C, Chandler JP. Surgical resection and adjuvant radiation therapy in the treatment of skull base chordomas. World Neurosurg. 2018;115:e115-21.

15. Smoll NR, Gautschi OP, Radovanovi I, Schaller K, Weber DC. Incidence and relative survival of chordomas: the standardized mortality ratio and the impact of chordomas on a population. Cancer. 2013;1119:2029-37.

16. Sun X, Hornicek F, Schwab JH. Chordooma: an update on the pathophysiology and molecular mechanisms. Curr Rev Musculoskelet Med. 2015;8(4):344-52. https://doi.org/10.1007/s12178-015-9311-x.

17. Takagi M, Demizu Y, Nagano F, Terashima K, Fujii O, Jin D, et al. Treatment outcomes of proton or carbon ion therapy for skull base chordoma: a retrospective study. Radiat Oncol. 2018;13(1):232. https://doi.org/10.1186/s13 014-018-1173-0.

18. Tsutsumi S, Akiba C, Suzuki T, Nakanishi H, Izumi H, Yasumoto Y, et al. Skull base chondroid chordoma: atypical case manifesting as intratumoral hemorrhage and literature review. Clin Neuroradiol. 2014;24(4):313-20. https://doi.org/10.1007/s00062-014-0321-7.

19. Walcott BP, Nahed BV, Mohyeldin A, Coumans JV, Kahle KT, Ferreira MJ. Chordoma: current concepts, management, and future directions. Lancet Oncol. 2012;13(2):e69-76. https://doi.org/10.1016/S1470-2045(11)70337-0.

20. Wynfold-Tomas D. P53 in tumour pathology: can we trust immunohistochemistry? J Pathol. 1992;166(4):329-30. https://doi.org/10.1 002/path.1711660402.

21. Yakkioui Y, Temel Y, Creytens D, Jahanshahi A, Fleischeuer R, Santegoeds $\mathrm{RG}$, et al. A comparison of cell-cycle markers in skull base and sacral chordomas. World Neurosurg. 2014;82(1-2):e311-8. https://doi.org/10.1016/j. wneu.2013.01.131

22. Yakkioui Y, van Overbeeke JJ, Santegoeds R, van Engeland M, Temei Y. Chordoma: the entity. Biochim Biophys Acta. 1846;2014:655-69.

23. Zakaria WK, HafezRF TAN. Gamma knife management of skull base chordomas: is it a choice? Asian J Neurosurg. 2018;13(4):1037-41. https:// doi.org/10.4103/ajns.AJNS_61_17.

\section{Publisher's Note}

Springer Nature remains neutral with regard to jurisdictional claims in published maps and institutional affiliations.
Ready to submit your research? Choose BMC and benefit from:

- fast, convenient online submission

- thorough peer review by experienced researchers in your field

- rapid publication on acceptance

- support for research data, including large and complex data types

- gold Open Access which fosters wider collaboration and increased citations

- maximum visibility for your research: over $100 \mathrm{M}$ website views per year

At BMC, research is always in progress.

Learn more biomedcentral.com/submissions 